\title{
Performance comparison of hip fracture pathways in two capital cities: Associations with level and change of integration
}

\author{
UNTO HÄKKINEN ${ }^{1}$ * \\ TERJE P HAGEN ${ }^{2}$ \\ TRON ANDERS MOGER ${ }^{2}$
}

${ }^{1}$ CHESS (Centre for Health and Social Economics), National Institute for Health and Welfare (THL), Finland

${ }^{2}$ Department of Health Management and Health Economics, University of Oslo, Norway

\begin{abstract}
Finland and Norway have health care systems that have a varying degree of vertical integration. In Finland the financial responsibility for all patient treatment is placed at the municipal level, while in Norway the responsibility for patients is divided between the municipalities (primary and long-term care) and state-owned hospitals. From 2012, the Norwegian system became more vertically integrated following the introduction of the Coordination Reform. The aim of the paper is to analyse the associations between different modes of integration and performance indicators. The data included operated hip fracture patients from the years 20092014 residing in the cities of Oslo and Helsinki. Data from routinely collected national registers, also including data from primary health and long-term-care services, were linked. Performance indicators were compared at baseline (before the Coordination Reform, i.e., 2009-2011), and trends were described and analysed by difference-in-difference methods. The baseline study indicated that hip fracture patients in Oslo, compared with those in Helsinki, had longer stays in acute hospitals. They used less institutional care outside of hospitals as well as more GP services and fewer other outpatient services. Mortality was lower, and the probability of being discharged to home within 90 days from the index day was higher. After the Coordination Reform, the length of stay in hospital was shorter and the length of the first institutional episode in Oslo was longer than before the Reform, demonstrating that the shorter hospital stays were more than compensated for by longer stays in long-term-care institutions. The number of patients institutionalised 90 days from the index day increased and the number of patients discharged to home within 90 days from the index day decreased in Oslo after the Reform while the opposite trends were observed in Helsinki. After the Reform, the performance differences between the two regions had decreased.
\end{abstract}

JEL classification: H11, H75, I18

Key words: integrated care, vertical integration, hip fracture, Finland, Norway

* Correspondence to: Unto Häkkinen, Centre for Health and Social Economics. National Institute for Health and Welfare. Mannerheimintie 166, Helsinki Finland P.O. Box 30, FI-00271 Helsinki, Finland. E-mail: unto.hakkinen@thl.fi.

Published: Online December 2018. In print January 2019. dx.doi.org/10.5617/njhe.4836 


\section{Introduction}

Integration and coordination have been pursued in many ways in different health systems, and there is a plethora of terms that have been variously described as integrated care, coordinated care, collaborative care, managed care, disease management, case management, etc. (Nolte and McKee, 2008). The common theme in all these approaches is the ultimate goal of improving the situation of patients with (complex) chronic health problems by overcoming issues of fragmentation by linking the services of different providers along a continuum of care (Campbell et al., 1998; Kodner and Spreeuwenberg, 2002). Analysts have distinguished different dimensions of integration, with the most common taxonomies differentiating the type, breadth, degree, and process of integration. Horizontal integration takes place between organisations and organisational units that are at the same level in the health care system. Vertical integration brings together organisations at different levels of a hierarchical structure. Integration of primary care and specialist health care is an example of vertical integration, while integration of primary health care and long-term care will in most countries serve as an example of horizontal integration (WHO, 2016).

Finland and Norway both have tax-based health care systems but with varying degrees of vertical integration. In Finland, the financial responsibility for all patient treatment is placed at the municipal level, making the system more vertically integrated, while in Norway the responsibility for patients is divided between the municipalities (primary and long-term care) and state-owned hospitals. From 2012, the Norwegian system, through means of the Coordination Reform, became more vertically integrated, as municipalities started to pay a fraction of the costs for treatment of their residents at the hospital level and also covered costs related to patients overstaying in hospitals, so-called bed blockers (Gaughan et al., 2015).

The main aim of the study was to evaluate whether different models of vertical integration were associated with the performance of the health care systems in the two countries' capitals, the cities of Helsinki and Oslo. We compared system performance at baseline (before the implementation of the Coordination Reform, i.e. 2009-2011) by using 15 performance indicators, including length of stay (LOS), the supplied volume of different types of services, the share of patients permanently discharged to home, costs indicators, and health outcomes measured by mortality. The effects of the Coordination Reform were analysed by describing time trends and by difference-in-difference (DID) methods.

We concentrate on hip fracture patients because they typically are old and frail and consume services along a pathway that includes hospital care, primary care, rehabilitation, and long-term-care services. The methodological innovation of our project is the linking of hospital and causes-of-death registers to the registers of primary and long-term care by using personal identification numbers. This linking makes it feasible to analyse the patients' complete care pathways. We delimit the analyses of each patient episode to a period covering two years, one year before and one year after the index day.

\section{Background}

\subsection{Institutional settings}

In Finland, municipalities have been responsible for arranging and financing health and social services. Many municipalities have merged their health and long-term service administrations, including the budgeting of these services, to improve the coordination and integration of services. Also, most hospitals are owned by federations of municipalities and are thus financed by municipalities by reimbursement methods decided locally (Vuorenkoski et al., 2008). Although the Diagnoses Related Group (DRG) system is used 
in most hospital districts, its prices and application are not centrally decided prospectively, and its main aim is not to motivate an increase in activity and efficient production of hospital services, but to equalise the municipal financing so that it is based on the precise use of services.

Since in Finland municipalities are responsible for financing all public health and long-term services and even other services (basic education, social services, day care, etc.), they have motives for developing local-level actions to contain total costs of care. For hip fracture patients, examples of local-level actions include integrated patient pathway interventions aiming to discharge the patient to home as soon as possible: in Lahti in 2006 (Hakala et al., 2014) and in Espoo in 2011. The local interventions have usually been made at the municipal level, sometimes creating considerable differences in care pathways even between neighbouring municipalities. For example, within the capital area of Helsinki, there was great variation between the municipalities in how rehabilitation and other activities following hospitalisation were organised (Mäkelä et al., 2007).

In Finland, it is widely accepted that the primary care provided for nonworking people is underfunded (Vuorenkoski et al., 2008), and many initiatives aiming to improve the quality and volume of primary health care have failed (Olsen et al., 2016). Improvement in the role of primary care is also the starting point of the health and social care reform which is being prepared in 2018.

The Norwegian model is more fragmented, because primary care and long-term-care services are organised and financed at the municipal level, while hospital services are organised and financed by health enterprises that are parts of larger state-owned units called Regional Health Authorities (Hagen and Kaarboe, 2006; Ringard et al., 2013). The Regional Health Authorities (RHAs) are financed by the central government using a combination of fixed DRG prices and risk-adjusted capitation for somatic/acute treatment. This model is mimicked between the RHAs and the local enterprises.

Better vertical integration of services has also been a policy aim in Norway, and the Coordination Reform represents a comprehensive policy package involving several measures to ensure the successful implementation and commitment of the parties (MoHC, 2009). Two new laws were implemented: the Norwegian Public Health Act and the Act of Municipal Health and Care Services, both aiming at reinforcing the municipalities' responsibility for public health. The two most important financial measures of the Coordination Reform were (a) municipal co-financing of patients treated in the state-owned specialist health care services, and (b) municipal financial responsibility for patients ready for discharge (Forskrift om medfinansiering av spesialisthelsetj, 2012). Municipal financial responsibility for patients ready for discharge was enforced by implementing a fee to reduce patient overstays in hospitals, so-called bed blocking (Gaughan et al., 2015). The fee was paid by the municipality to the hospitals for patients declared ready for discharge who needed services from the municipalities but were unable to leave hospital because of a lack of municipal services. The hospitals had to notify the municipalities in advance about patients who needed municipal services. The fee was set to approximately 535 EUR per day (4000 NOK) in 2012 and paid from day one after the patient was declared ready for discharge ( 1 EUR $=7.47 \mathrm{NOK}$, which was the exchange rate in 2012). Also included in the reform package was an economic stimulus for the municipalities to build up services to tackle the increased care burden. Initial analyses indicate that the fee reduced the LOS in hospitals for the relevant patients (Melberg and Hagen, 2016).

The Helsinki University Hospital also introduced a fine to reduce bed blocking in 2007 to increase the efficiency of the hospital. This fine was abolished in September 2009 but reintroduced in July 2011. The fee was 365 EUR per day in 2011, 465 EUR per day in 
2012, and 600 EUR per day in 2013 and 2014, that is, much higher than the average cost per day in health centres, rehabilitation institutes, and nursing homes (Appendix Table 1).

\subsection{Empirical expectations}

Different incentives in the two cities might affect processes, costs, and patient outcomes. For key variables, we are able to derive empirical expectations. First, length of hospital stay at baseline should be shorter in Helsinki than in Oslo, mainly because of the fee for bed blockers that has been used for several years in the Helsinki area. The fee was abolished in September 2009 and then reintroduced in mid-2011. However, the municipalities in Finland act as fund holders and can pressure hospitals to keep efficiency at a high level (Rehnberg and Häkkinen, 2013). Even if the fee were abandoned for a period, we do not expect an immediate increase in the LOS. Because Oslo introduced a fee from 2012, we expect the LOS to be reduced and to gradually approach the Helsinki level. Second, we expect an inverse relationship between LOS in hospitals and LOS in institutional care following an acute hospital stay (i.e., a short hospital stay in the acute phase will be followed by a comparatively longer rehabilitation period outside the hospital and vice versa). This expectation follows from the assumption that the need for rehabilitation will be more or less constant both across cities and over time.

How costs of institutional care will be affected is harder to say. In general, we expect costs per day to be higher in hospitals than in rehabilitation and long-term institutions, mainly because of differences in number of staff and their wage levels. If the reduction in LOS in hospitals equals the increase in LOS outside hospitals, costs will be higher in Oslo than in Helsinki at baseline and will approach the Helsinki level after the reform, if the LOS outside hospitals increases more than the LOS in hospitals is reduced, the conclusions are less clear. Since Helsinki (as all municipalities in Finland) is responsible for overall financing for social and health services, the city has clearer incentives to contain the total cost of care than does Oslo.

Although there are no available empirical analyses, descriptive information on the primary care systems suggests that Norway has allocated more resources to primary doctor services than Finland has (Häkkinen and Jonsson, 2009). Thus, the role of primary care in treating hip fracture patients can be assumed to be more important in Oslo, which might affect the possibilities for patients to be discharged to home and to avoid institutionalisation.

For outcome measures such as mortality, we do not have explicit expectations.

\section{Data and methods}

\subsection{Inclusion and exclusion criteria}

The study analysed annual cohorts of operated hip fracture patients from Oslo and Helsinki in the years 2009-2014. The construction of data was based on a common protocol using links to routinely collected national registers and statistics on hospital discharges, use, and causes of death developed in the EuroHOPE (European Health Care Outcomes, Performance and Efficiency) project (http://www.eurohope.info) (Häkkinen et al., 2013; Moger and Peltola, 2014; EuroHOPE, 2016). For this study, we extended the approach to primary health services, social services, and long-term-care services by collecting data on these services from municipal registers. In addition, we linked in data on socioeconomic variables provided by the national statistical offices.

Episodes of hip fracture start with an acute phase in hospital immediately after the event. The beginning of the episode, the index date, was defined as the first hospital day of a hospital admission with the primary diagnosis of hip fracture (ICD-10 S72.0-S72.2), using 
five exclusions. First, we excluded all patients who had a hospital admission related to a hip fracture during the 365 days prior to the index date. Second, we excluded patients who had not had surgery during the first hospital admission. Third, we excluded foreigners and patients with an incomplete personal identity number in the registers. Fourth, we excluded patients under the age of 50, since in younger patients, hip fractures are usually caused by high-energy trauma and are often associated with other serious injuries. Finally, we excluded patients who were in hospital or in long-term care for all 90 days before the index admission to make the patient cohort more homogenous (Sund et al., 2011). Since an important outcome measure is how quickly patients are discharged to home, it is reasonable to consider only patients who were not institutionalised before their hip fracture.

\subsection{Variable definitions}

To track patients' movements along the care pathway, we constructed a STATE variable that describes in which place or state the patient is each day 365 days before and 365 days following the index day (Sund and Häkkinen, 2016). The STATE variable is based on the idea that a patient can be at only one specific place each day and conveys information about 1) the patient's fundamental state (dead, alive at home, or alive at an institution), 2) the type of care (hospital, rehabilitation, nursing home, home nursing, or others), 3) the main diagnosis and intensity of the treatment (i.e., acute care or non-acute), and 4) types of outpatient visits.

Based on the STATE variable and some other common protocols we defined five groups of performance variables:

Variables describing length of stay included length of the first acute hospital admission and length of the first institutional episode, where the first institutional episode is the sum of the days in the acute hospital stay and days in rehabilitation and long-termcare institutions like nursing homes during the first 90 days after the index day if a patient is transferred to these institutions immediately after the surgery admission.

Variables describing service use included the number of inpatient days, the number of GP visits, the number of other health care visits, and the number of home care visits all calculated for a one-year period after the index day. Home help included both practical assistance and home nursing because these services cannot be distinguished in the Finnish data.

Variables describing emplacement included the share of patients permanently discharged to home within 90 days from the index day, the share of patients permanently discharged to home without help within 90 days, the share of patients institutionalised within 90 days, and the share of patients institutionalised within one year from the index day. Here, 'permanently' means that a patient must be at least two weeks continuously at home after discharge, that is, without being transferred to any inpatient care (including respite care) within that period. 'Institutionalisation' was defined as the patient being in inpatient care all days during the follow-up time (90 days or one year).

Variables describing costs included the cost of the first hospital episode and oneyear costs. Costs were measured by using the standard Finnish cost of specific cost items (Kapiainen et al., 2014), which were deflated to the 2014 price level. In acute hospital care, costing was calculated by regressing the cost at the individual level, using data from patients treated at the Helsinki University Hospital (hospital days, use of specific procedures, and type of fracture), against resource items. Patient-level costs for both Oslo and Helsinki were then derived using the coefficients of the regression models. Descriptions of services and costing methods are shown in the Appendix, Table 1. Data on some cost items (e.g., 
prescribed drugs and private treatments) were not available for Oslo. Their share of the total cost was about $3 \%$ in the Finnish data.

Variables describing mortality included 30-day, 90-day, and one-year mortality.

\subsection{Analytical approach}

We first compared the two cities at baseline using data from before the Coordination Reform (i.e., the years 2009-2011). A preliminary analysis indicated that there were differences in service use between patients from the two cities before the index day (Figure 1). The most important difference was the share of patients using home help services. In Oslo, about $30 \%$ of patients lived at home and got continuous home help services before the hip fracture admission. In Helsinki, the corresponding figure was $15 \%$. On the other hand, in Helsinki about $71 \%$ (in Oslo, 61\%) of patients lived at home without continuous help. We did not have any information about whether these differences reflect differences in the functional ability of the patients. Hence, we performed risk adjustment in two different ways. First, we adjusted, using standard patient covariates, age (in 5-year intervals), gender, year of admission, and ICD-10 type of fracture as control variables (model M1). Second, we also included the previous 90-day use of services (hospital care, institutional care, and home help services), education, and income ${ }^{1}$ as control variables (model M2).

The following GLM specification was used for analysing the variation in the 15 performance indicators (Y, see Table 1):

$g\left(E\left(Y_{i}\right)\right)=\beta_{0}+\beta_{1}$ city $_{i}+\beta_{2}$ covariate $_{i 1}+\cdots+\beta_{k}$ covariat $_{i k}$

For dichotomous performance indicators (mortality, indicators on whether discharged to home or institutionalised), we assumed a logit model. Further, we assumed hospital days and visits were generated by Poisson-like processes with overdispersion. Hence, a negative binomial model with log-link was used. Because cost data are commonly skewed, we assumed a gamma model, also with log-link, for the cost indicators. Results are presented as marginal unadjusted and adjusted differences between the cities, as captured by $\beta_{1}$ in the equation. Because there are no interaction terms between city and covariates in the model, the effects of covariates are assumed to be similar across cities. For dichotomous performance indicators, the marginal effect describes the difference between Oslo and Helsinki in percentage points, whereas for other indicators, the differences are given in units (number of hospital days, visits, and EUR).

Second, the effects of the Coordination Reform were analysed by describing time trends in performance indicators and by using the DID method. The Reform was implemented simultaneously in all of Norway, so no sensible control groups exist. Thus, the Helsinki area is used as a control group. The DID part of the model was specified as follows:

$Y_{i}=\beta_{0}+\beta_{1}$ period $_{i}+\beta_{2}$ city $_{i}+\beta_{12}$ period $_{i}$ city $_{i}+\varepsilon_{i}$

The interaction term $\beta_{12}$ between period $(0=2009-2011,1=2012-2014)$ and city $(0=$ Helsinki, $1=$ Oslo $)$ in the regression model captures the DID effect of the Coordination Reform. The DID estimates were made without other covariates (unadjusted) and adjusted

\footnotetext{
${ }^{1}$ We measured income by annual gross income of patients. In the Finnish data, exact income was available, whereas in the Norwegian data, income was measured in 11 income groups, defined in NOK. We made the incomes comparable as follows. First, we divided the Finnish patients into Norwegian income groups using purchasing power parities (PPPs) for the year 2014. We used the Finnish mean income (EUR) in each group as measure of income in year 2014. Earlier years' income was calculated by the use of national consumer price indices.
} 
using the two above-mentioned risk-adjustment models (except year of admission), similar to what was done in the baseline analysis. These terms are not shown in the DID equation above to save space. As in the baseline analysis, marginal unadjusted and adjusted effects describing the differences between Oslo and Helsinki are presented. Applying nonlinear models, as in Equation 1, within a DID framework is challenging, and leads to inconsistent estimates of the effect (Lechner, 2011, pp. 195-203). Consequently, the DID analysis in Equation 2 is based on OLS models because the samples are large, but bootstrapped standard errors based on 5000 replications were used to relax normality assumptions for the inference. To indicate possible DID effects, we also show time trends in graphs for each performance indicator before and after the Coordination Reform.

Figure 1: Share (\%) of patients at home with and without help before and after hip fracture, 2009-2013

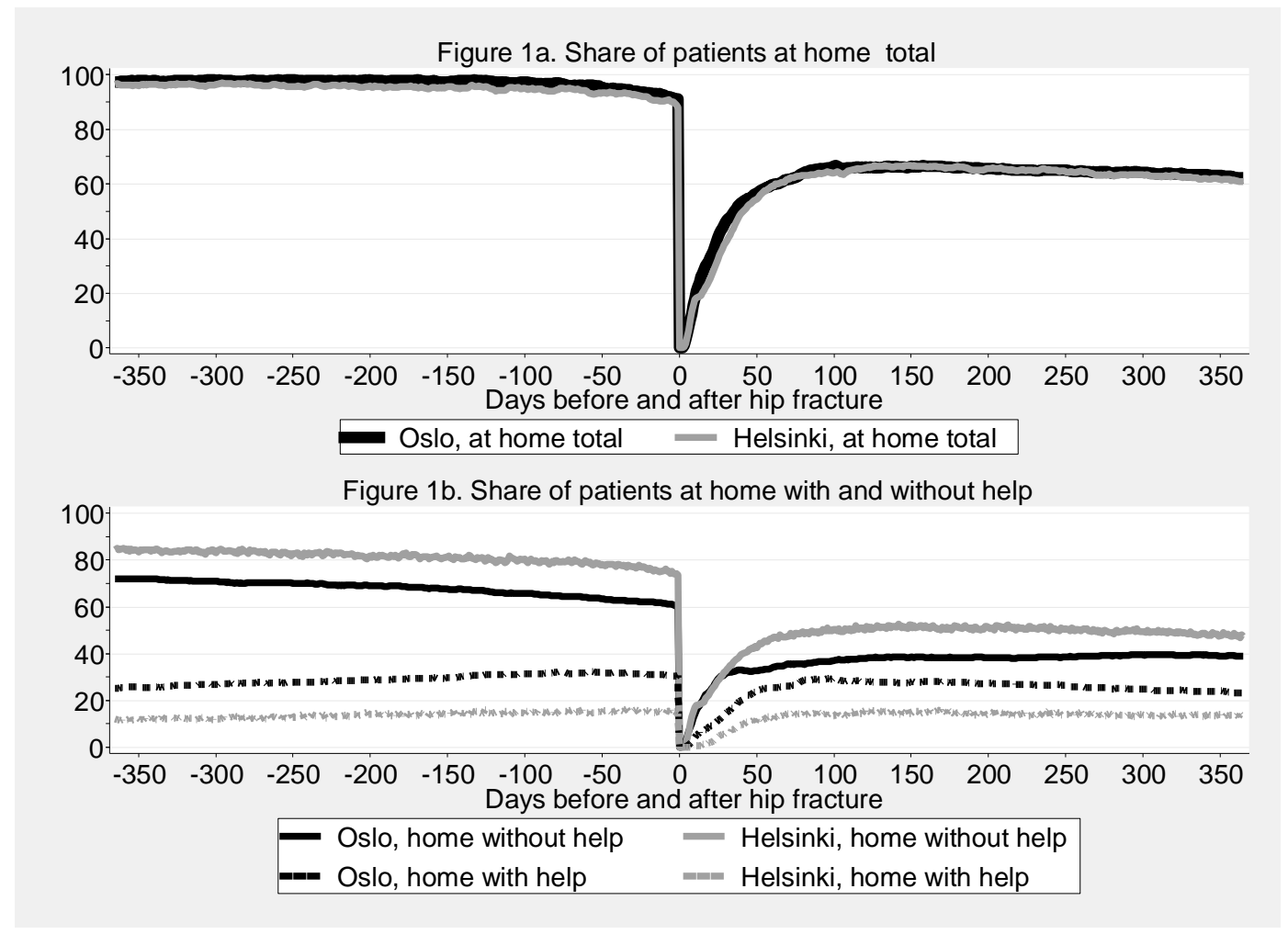

As a sensitivity analysis, we combined the DID model (Equation 2) with propensity score matching on the two sets of risk-adjustment variables and bootstrapped standard errors (Villa, 2016) using the default Epanechnikov kernel function with a bandwidth of 0.06. This bandwidth did not exclude any observations from the analysis. Bootstrapping was made using 5000 replicates. To estimate any causal effect, the DID method is based on several assumptions (Lechner, 2011), of which the common trend assumption is the most important in our case. The common trend assumption requires that in the absence of the Reform, the differences between Oslo and Helsinki are constant over time. There is no formal statistical 
test for the assumption ${ }^{2}$ and we have data for only three years. Visual inspection (Figure 3 ) cast doubt about whether the annual trend for all performance indicators was the same in the two cities before the Reform.

From Oslo we could follow patients only to the end of the year 2014; so we cannot calculate variables requiring a 365-day follow-up for patients treated in 2014. For variables that need a shorter follow-up, we excluded patients with index data during the month(s) of the year 2014 (e.g., December in measuring 30-day mortality and the last three months in measuring 90-day mortality).

\section{Results}

\subsection{Comparison of baseline performance 2009-2011}

Before the Coordination Reform, the LOS of the first hospital stay (the surgery admission) was about 3 days longer in Oslo than in Helsinki, while the LOS for the first institutional episode was about 5-6 days shorter (Table 1, adjusted figures). In Oslo, patients were discharged to home somewhat earlier than in Helsinki; and after 90 days the rate for a permanent discharge to home was 4-8 percentage points higher than in Helsinki. However, patients discharged to home in Oslo more often received municipal home help services (practical assistance or home nursing) than did patients in Helsinki, even after adjusting for the use of home services before the index day (Model M2).

There were also differences in the use of ambulatory and primary care services. After a hip fracture, the annual number of GP visits was about 1 visit per patient higher in Oslo than in Helsinki, whereas the number of outpatient visits in hospitals and to specialists was about 3-4 visits more per patient in Helsinki than in Oslo. The share of patients being institutionalised within 90 days was 3-6 percentage points lower in Oslo than in Helsinki, while in the one-year follow-up there were no differences between the cities (Table 1).

Because costs were higher in acute hospital inpatient care than for nursing homes and other inpatient care, cost differences between the two cities for the first institutional episode were not significantly different (except model M2) even though the LOS for the first institutional episode was significantly higher in Helsinki.

The city differences in the one-year cost varied according to variables used for risk adjustment: when previous use of services and socioeconomic status were controlled for, the one-year costs were 4800 EUR (over 10\%) lower in Oslo than in Helsinki. Also, age-, sex-, and type-of-fracture-adjusted costs were 2000 EUR lower in Oslo. In both cities, about $80 \%$ of the cost was devoted to inpatient care (Figure $2 \mathrm{a}$ ). The composition of cost varies: in Helsinki, the share of the total cost of all inpatient care $(81.5 \%$ vs $79.7 \%)$ and of all outpatient visits (including other visits) (6.7\% vs $2.2 \%)$ was higher, and the share of the total cost of home care was lower than in Oslo (11.9\% vs $18.1 \%)$.

\footnotetext{
${ }^{2}$ We performed a simple test of the assumption by estimating the Equation (1) by including a time trend (linear and logarithmic) and its interaction with the city variable using the baseline data (2009-2011). Interactions were significant for 7 of 15 indicators. We found significant interactions for variables describing the share of patients discharged to home without help (positive sign), the length of the first acute (surgery) hospital admission (negative), the number of hospital days during one year (positive), other doctor visits (positive, only logarithmic trend), home help visits (negative), and the cost of the first hospital episode (negative).
} 


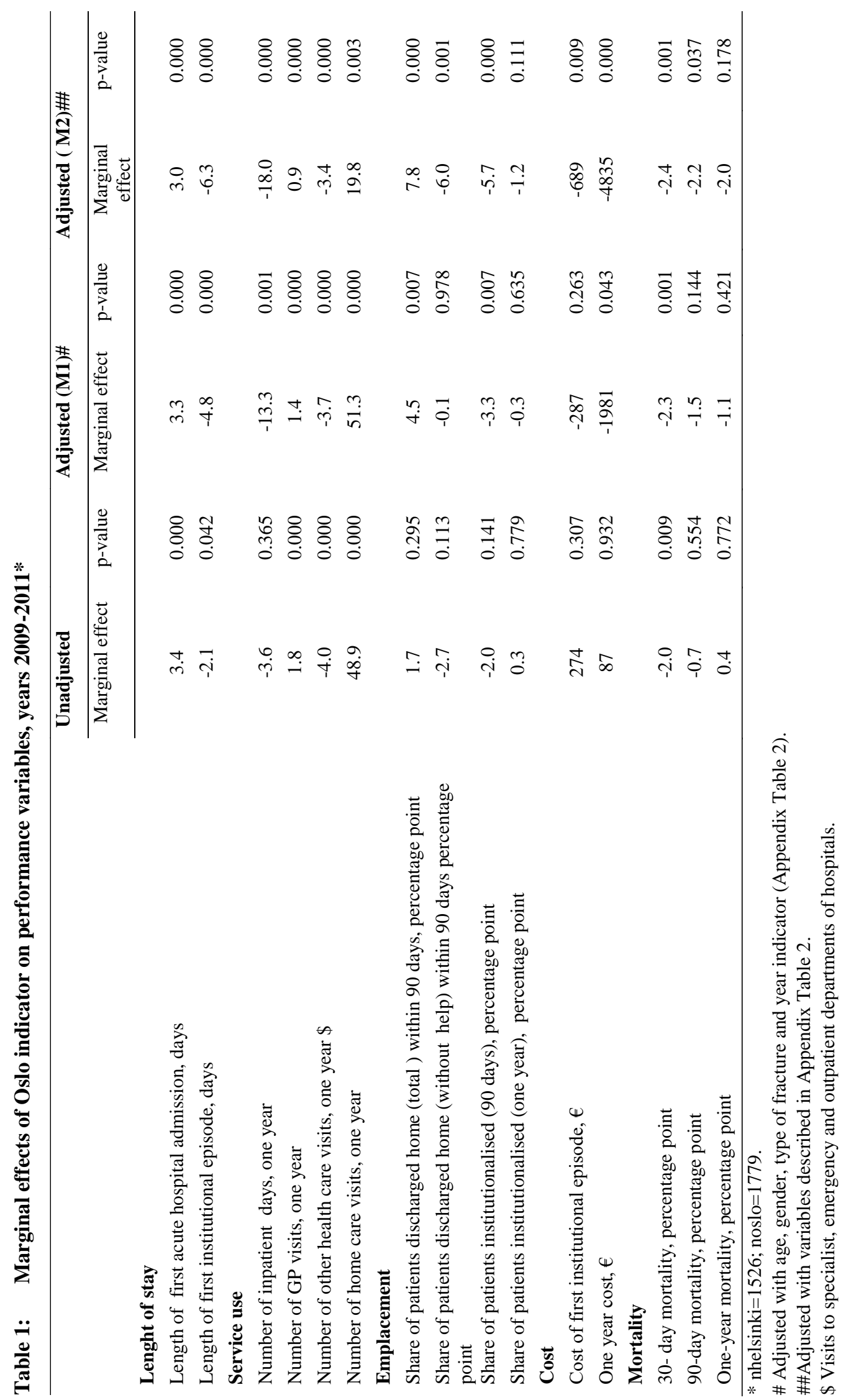


Figure 2: Age, sex, and type of fracture standardised one-year cost 2009-2011 and 2012-2013
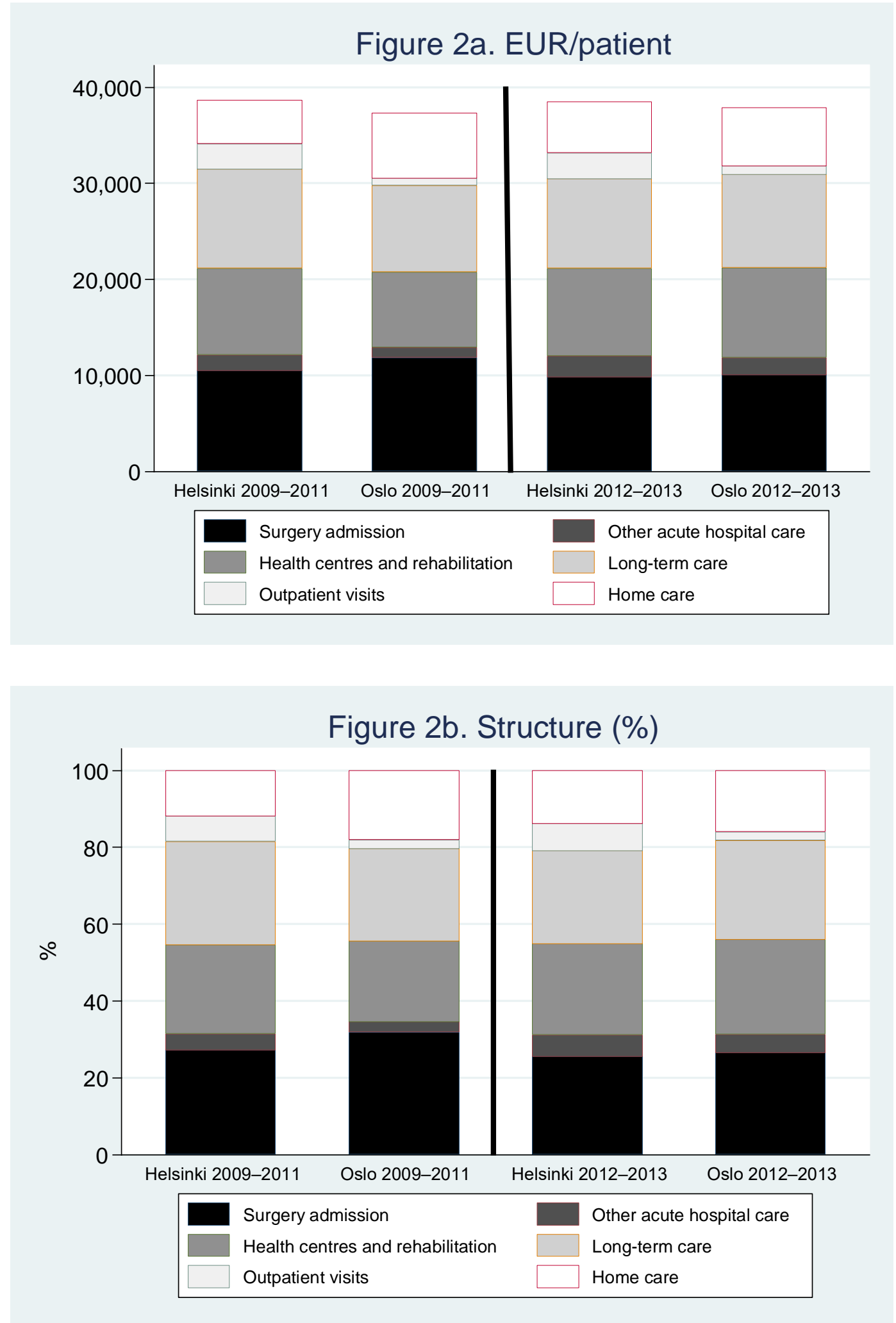

The 30-day mortality was about 2 percentage points higher in Helsinki, but there were no clear differences between the cities in 90-day and one-year mortality, except in 90- 
day mortality with an adjustment for a full set of variables (M2), in which case mortality was 2 percentage points higher in Helsinki than in Oslo.

\subsection{Evaluation of the Coordination Reform}

Our evaluation of the Coordination Reform is based on interpretations of the descriptive time trends presented in Figure 3 as well as the DID results presented in Table 2. One of the main aims of the Coordination Reform of 2012 was to reduce the use of acute hospital care, and introducing the fee for bed blockers was one of the measures in this respect. As intended, the LOS of the first (acute) hospital episode decreased, in some cases by 4-5 days (depending on the type of risk adjustment), but a decreasing trend can also be observed in Helsinki (Figure 3a). Thus, the DID estimates (Table 2) show a smaller effect (2 days). Further indications of the effects of the fee for bed blockers can be found in Figure 3a, which indicates that abolishing the fee for bed blockers at the Helsinki University Hospital increased the LOS between the years 2009 and 2011.

However in Oslo, the LOS of the first institutional episode has increased (i.e., the small decrease in acute care was followed by an increase in other inpatient care) after the Reform, while in Helsinki it has been rather constant. The DID estimates show increases of 4-6 days in Oslo relative to Helsinki because of longer stays in Helsinki in 2010. The number of inpatient days during the first year after fracture had already increased in Oslo before the Reform and in 2013 were at the same level as in Helsinki (Figure 3b).

Figure 3: Trends in performance measures in Oslo and Helsinki: age, gender, and type of fracture, standardised figures
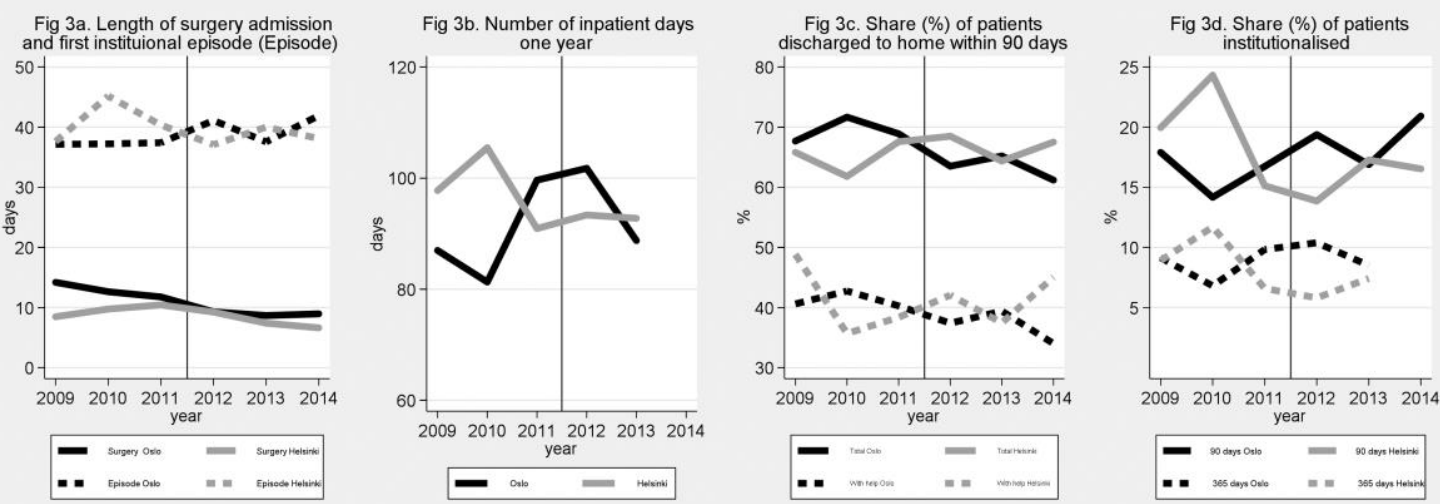

Fig 3e. Number of GP and other visits
to a doctor, one year
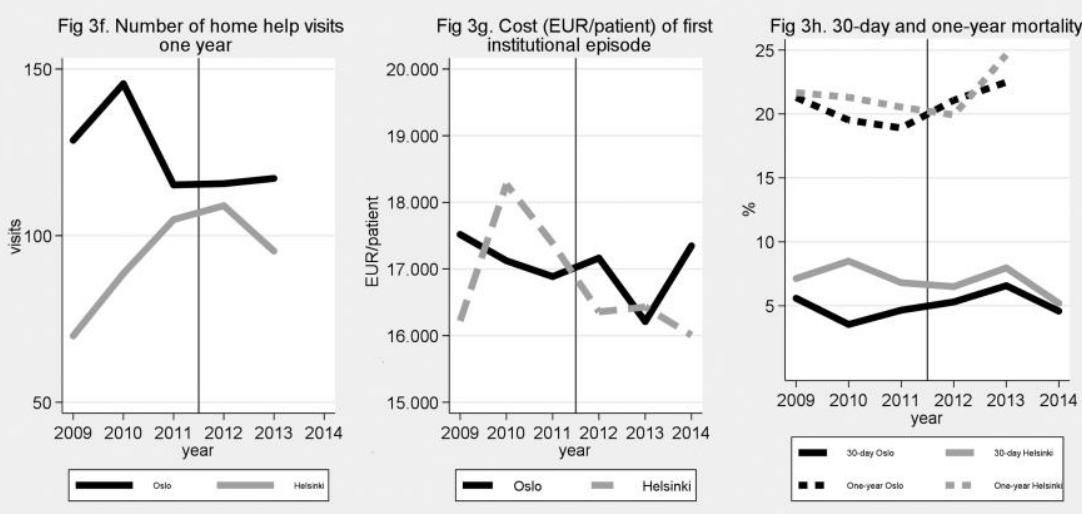


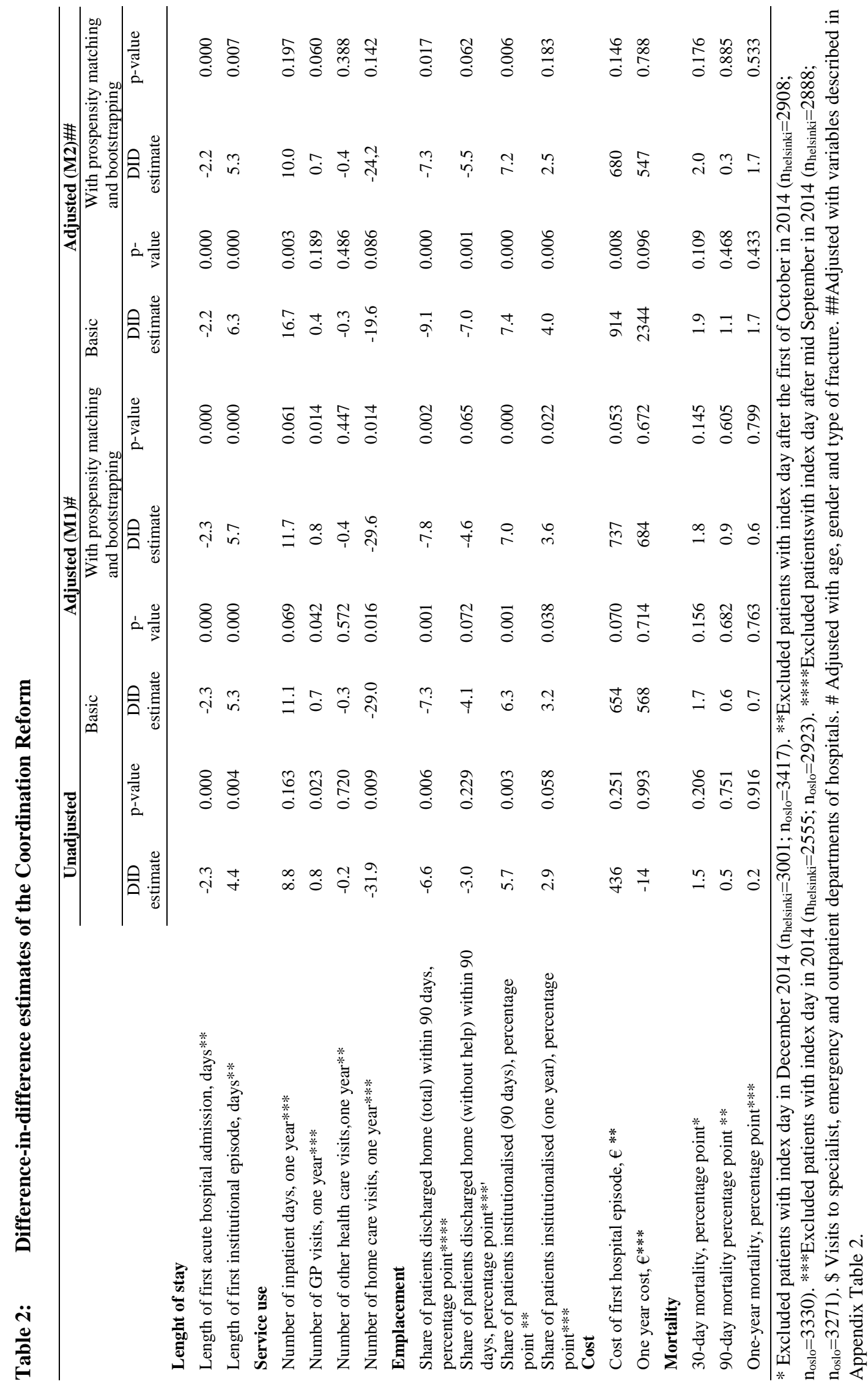


The share of patients institutionalised within 90 days of the index day increased in Oslo after the Coordination Reform (Figure 3d), but the positive DID estimates (6-7 percentage points) also reflect a decrease in the share in the share of institutionalised in Helsinki after 2010. Just as the number of inpatient days increased after one year, so too did the share of patients in institutions one year after hip fracture in Oslo in 2011. Again, the positive DID estimate is partly due to a high value in Helsinki before the Reform.

After the Coordination Reform, the share of overall discharges to home as well as of discharges to home without help decreased in Oslo by around 5 percentage points. The negative DID estimate (7-9 percentage points) for overall discharges to home reflects both a decrease in Oslo and an increase in Helsinki. The DID estimate for discharges to home without help was smaller (3-7 percentage points), reflecting that the share in Helsinki was quite high in 2009 (Figure 3c).

The Coordination Reform seems to be associated with increased use of GP visits (which is consistent with the policy aims) but also seems to be associated with reduced use of home services because more patients were discharged to municipal institutions.

After the Reform, the cost of the first institutional episode decreased somewhat in Oslo in 2013, but increased in 2014 (Figure 3g). In Helsinki, there has been a decreasing trend since the year 2010. Risk-adjusted DID estimates are positive, but in most cases not significant. The effects of the Reform for the one-year cost were not significant. However, after the Reform, the differences in the cost composition between cities have changed. In Oslo, the cost share of all institutional care is even higher than in Helsinki ( $81.7 \%$ vs $79.2 \%)$, the cost share of home help services is almost at the same level (16.0\% vs $13.8 \%)$, while the cost share of outpatient visits is still clearly lower (2.3\% vs $7.0 \%$ ) because of the high use of hospital outpatient services in Helsinki (Figure 2).

The differences in 30-day mortality between the cities have decreased, and the DID estimates indicate a non-significant increase in mortality after the Reform in Oslo relative to Helsinki (Table 2). As can be seen from Figure 3h, one-year mortality has increased somewhat in both cities during recent years.

\section{Conclusions}

The main aim of the study was to evaluate whether different models of vertical integration were associated with the performance of the health care system and with the outcomes for hip fracture patients. We have been specifically interested in studying the effects of the Coordination Reform implemented in Oslo in 2012. As far as we know, this is the first international comparison where register data from primary and long-term-care services are linked with hospital discharge data and mortality registers.

Our baseline study from 2009 to 2011 demonstrated significant differences in the service structure across the two capital cities. Prior to acute admissions, hip fracture patients in Oslo were more often at home with help than were hip fracture patients in Helsinki $30 \%$ vs $15 \%$ ). In accordance with our expectations, the results indicate that hip fracture patients in Oslo had a longer stay in acute hospitals before the Reform. In addition, in Oslo (compared to Helsinki), the use of institutional care (including both hospitals and long-termcare institutions) was lower, the use of GPs was higher, and the use of outpatient services with specialists was lower, 30-day mortality was lower, and the share of patients discharged to home after 90 days was higher. Some of these results were sensitive to the risk-adjustment method. These results might indicate that there are more developed primary and home help services in Norway than in Finland, as assumed based on descriptive information about the primary care systems (Häkkinen and Jonsson, 2009). The results also indicate that financial integration, as is the case in Helsinki, did not guarantee lower use of resources. 
The effects of the Coordination Reform have been seen as modest in preliminary analyses, with a reduction in hospital LOS as its main achievement, but also with nonsignificant increases in readmissions and stable mortality rates as notable achievements, too (Melberg and Hagen, 2016). The comparison with Helsinki gives a sharper picture. Although the Reform shortened the length of the first acute stay in hospital, it increased the length of the first institutional episode, demonstrating that the shorter hospital stays were more than compensated for by longer stays in long-term-care institutions. Our cost estimates did not show significant changes, indicating that the Coordination Reform's aim of reducing resource use in hospitals has been achieved. The reduction is, however, compensated by increases in costs in other parts of the health care system, at least in the short run and for this specific group of patients.

The analyses of trends in short-term institutionalisation and in patients discharged to home after 90 days also showed less-desired results from a Norwegian perspective. The sharp reduction in hospital LOS has taken its toll in Oslo, and the municipality might not have been fully prepared for the increased care burden created by the reduction in hospital LOS. More generally, after the Reform, the performance differences between the two regions have decreased.

Unfortunately, we did not have any data on functional ability (such as measures of activities in daily living) of patients from Helsinki. The only opportunity for risk adjustment was to use age and gender as covariates in adjusted models and to make a sensitivity analysis by employing the previous use of different services and socioeconomic status as additional covariates. Thus, in the sensitivity analysis, we assume that the previous use of services is closely related to the functional ability of patients. Generally, the sensitivity analysis does not change our results and main conclusions much. It is expected that the most important difference is that the additional adjustment affects the results of variables related directly to the use of home services (discharge to home without help and number of home help visits during one year).

In addition to using traditional mortality indicators, we measured performance by describing the increase in the probability of swift discharges to home (with and without help) and the reduction in institutionalisation, which have been policy aims in both countries. These measures can be used as a proxy variable for outcomes if we can assume that the measures reflect the functional status. However, we cannot confirm that the functional status of persons living at home, with or without help, or in institutions is the same between the cities or whether the variations reflect differences in policy priorities.

Our approach to measure cost by means of resource use has both advantages and disadvantages. The main advantage is that we can avoid concerns about differences in costaccounting systems and prices between the countries and producers. The main weakness of the approach is that it does not take into account the differences in unit prices of resource items. For example, the cost of inpatient days, of procedures, or of visits might vary owing to differences in inputs (personnel, working time, etc.). Thus, we compared resource use, not actual spending so our cost measure does not necessarily reflect the actual cost differences. In addition, since data on home help were not measured using the same units (visits in the Helsinki area and hours in Oslo), our estimates are based on the assumption that one hour equals two visits.

The DID method is based on common trend assumption before the Reform. It is difficult to rule out any other changes in treatment practice or in organisation occurring in the two countries, changes that are unrelated to the Coordination Reform. This means that the DID estimates must be interpreted with caution, and that any firm causal conclusions on the effects of the Reform cannot be reached. 


\section{Acknowledgements}

The data gathering and analyses were funded by the Health Programme of the European Union (grant number 664691 / BRIDGE Health) and the Research Council of Norway (grant number 229092 / Comparative effectiveness analyses of coordinated care initiatives in three Nordic countries). Unto Häkkinen acknowledges financial support from the Yrjö Jahnsson Foundation and the Finnish Society for Health Economics. The paper was discussed at the 38th Nordic Health Economics Study Group Meeting in Helsinki, August 23-25, 2017. We would like to thank seminar participants and in particular our discussant, Øystein Døhl, for valuable comments.

The Norwegian part of the project was approved by Norwegian Regional Committees for Medical and Health Research (2013/1321) and the Norwegian Data Protection Authority (37355). In Finland, permission to use the register data was obtained from owners of the registers.

\section{References}

Campbell, H., Hotchkiss, R., Bradshaw, N. and Porteous, N. (1998). Integrated care pathways. British Medical Journal, 316, 133-137.

EuroHOPE. (2016). Building register-based performance indicators for hip fracture using individual-level administrative health care data. [Online]. http://www.eurohope.info/. [Accessed August 27th 2016].

Forskrift om medfinansiering av spesialisthelsetj. FOR-2011-06-29-695. (2012). Forskrift om kommunal medfinansiering av spesialisthelsetjenesten og kommunal betaling for utskrivningsklare pasienter (2012-01-01) [Online]. Available: Lovdata [Accessed March 3t1.2012].

Gaughan, J., Gravelle, H. and Siciliani, L. (2015). Testing the Bed-Blocking Hypothesis: Does Nursing and Home Care Supply Reduce Delayed Hospital Discharges? Health Economics, 24(Suppl. 1), 32-44.

Hagen, T. P. and Kaarbøe, O. A. (2006). The Norwegian hospital reform of 2002: Central government takes over ownership of public hospitals. Health Policy, 76, 320-33.

Hakala, M., Malmivaara, A., Eskelinen, J., Toivonen. U., Haapala, J., Valjakka-Heimola, M., Mikkelsson, M., and Häkkinen, U. (2014). Kuntoutusosaston perustamisen vaikutus lonkkamurtumapotilaiden hoitotuloksiin. Suomen Lääkärilehti (Finnish Medical Journal), 69, 319-23.

Häkkinen, U., Iversen, T., Peltola, M., Seppälä, T., Malmivaara, A., Belicza, E., Heijink, R., Fattore, G., Numerato, D., Medin, E., and Rehnberg, C. (2013). Health care performance comparison using a disease-based approach: the EuroHOPE project. Health Policy, 112, 100-109.

Häkkinen, U., and Jonsson P.M. (2009). Harnessing diversity of provision. In Magnussen, J., Vrangbæk, K. and Saltman, R. B. (eds). Nordic health care systems: Recent reforms and current policy challenges (pp.198-213). Open University Press, Berkshire.

Kapiainen, S., Väisänen, A. and Haula, T. (2014). Terveyden- ja sosiaalihuollon yksikkökustannukset Suomessa vuonna 2011. THL raportti 3/2014.

Kodner, D.L. and Spreeuwenberg, C. (2002). Integrated care: meaning, logic, applications, and implications--a discussion paper. International Journal of Integrated Care, (2), 1-6.

Lechner, M. (2011). The Estimation of Causal Effects by Difference-in-Difference Methods. Foundations and Trends in Econometrics, 4(3), 165-224.

Melberg, H. O. and Hagen, T. P. (2016). Liggetider og reinnleggelser i somatiske sykehus før og etter samhandlingsreformen. Tidsskrift for omsorgsforskning, (2), 143-58. 
Moger, T. A. and Peltola, M. (2014). Risk adjustment of health-care performance measures in a multinational register-based study: A pragmatic approach to a complicated topic. Sage Open Medicine, (2), 1-11.

MoHC. (2009). Report No. 47 to the Storting (2008-2009): The Coordination Reform, Proper treatment - at the right place and right time. Oslo: Ministry of Health and Care.

Mäkelä, M., Häkkinen, U., Juslin, B., Koivuranta-Vaara, P., Liski, A., Lyytikäinen, M., and Laine, J. (2007). Sairaalasta kotiin. Erikoissairaanhoidosta alkaneet hoitoketjut pääkaupunkiseudun kunnissa, Stakes työpapereita, 3/2007.

Nolte, E. and McKee, M. (2008). Integration and chronic care: a review. In Nolte, E. and McKee, M. (eds.) Caring for people with chronic conditions. A health system perspective (pp. 64-91). Open University Press.

Olsen, K., Anell, A., Häkkinen, U., Iversen, T., Ólafsdóttir, T. and Sutton, M. (2016). General practice in the Nordic countries. Nordic Journal of Health Economics, 3(1), 41-55.

Rehnberg, C. and Häkkinen, U. (2013). Productivity differences in Nordic hospitals: can we learn from Finland? In Iversen T, Kittelsen S, (eds). Nordic economic Policy Review, Challenges in health care financing and provision. (pp. 277-315).Nordic Council of Ministries.

Ringard, A., Sagan, A., Sperre Saunes, I. and Lindahl, A. K. (2013). Norway: Health system review. Health Systems in Transition, 15(8), 1- 162.

Sund, R. and Häkkinen, U. (2016). Using registry data to compare health care efficiency. In Cylus, J., Papanicolas, I. and Smith, P., (eds.) Health System Efficiency. How to make measurement matter for policy and management (pp. 53-74). European Observatory on Health Systems and Policies, Policy Series 46.

Sund, R., Juntunen, M., Lüthje, P., Huusko, T. and Häkkinen, U. (2011). Monitoring the performance of hip fracture treatment in Finland. Annals of Medicine, 43( Suppl. 1), 39-46.

Villa, J. (2016). Diff: Simplifying the estimation of difference-in-difference treatment effects. The Stata Journal, (16), 52-71.

Vuorenkoski, L., Mladovsky, P. and Mossialos, E. (2008). Finland: Health system review. Health Systems in Transition, 10(4), 1-168.

WHO. (2016). Integrated care models: an overview. Working document (available: http://www.euro.who.int/_data/assets/pdf_file/0005/322475/Integrated-care-modelsoverview.pdf?ua=1).

(C) 2018 by the author(s). This article is an open access article distributed under the terms and conditions of the Creative Commons Attribution license (http://creativecommons.org/licenses/by/4.0/). 


\section{Appendix}

Appendix Table 1: $\quad$ Definition of services and their costing

\begin{tabular}{|c|c|c|}
\hline Service & Method & Value in 2014 \\
\hline $\begin{array}{l}\text { Acute hospital care (university, } \\
\text { specialised hospitals, private } \\
\text { (Norway)) hospitals. }\end{array}$ & $\begin{array}{l}\text { Based on cost function } \\
\text { estimated using individual } \\
\text { level cost data from } \\
\text { Helsinki university hospital } \\
\text { (2014 prices). }\end{array}$ & $\begin{array}{l}\text { First acute hospital episode: } \\
\text { Cost } €=1810 * \text { group } 1 \text { - } \\
1221 * S 720+510 * \operatorname{los}+5119 \\
\text { where group } 1=1 \text { if operation is } \\
\text { partial prosthesis, } 0 \text { if other } \\
\text { operation; S72.0=1 if main } \\
\text { diagnosis is ICD-10: S72.0, } 0 \text { if } \\
\text { ICD-10: S72.1 or S72.2; } \\
\text { los=length of stay. } \\
\text { One year cost of acute care: } \\
\text { Cost } €=5894 * \text { proc_365 }+ \\
284 * \text { los_365_h }+709 * \text { los_365_o + } \\
1678 \text { where proc_365 = number of } \\
\text { hip fracture related operations } \\
\text { during } 365 \text { days; } \\
\text { los_365_h=number of days in } \\
\text { acute care during } 365 \text { days with hip } \\
\text { fracture as main diagnosis; } \\
\text { los_365_o numbers days in acute } \\
\text { care during } 365 \text { days with other } \\
\text { than hip fracture as main diagnosis. }\end{array}$ \\
\hline $\begin{array}{l}\text { Rehabilitation and non-specialised } \\
\text { short term inpatient care. In Helsinki } \\
\text { include short-term care (length of stay } \\
\text { less than } 90 \text { days in health centres) } \\
\text { and care in psychiatric departments }\end{array}$ & $\begin{array}{l}\text { Standard cost estimates } \\
2011 \text { (Kapiainen et } \\
\text { al.,2014) }\end{array}$ & $226.2 € /$ day \\
\hline $\begin{array}{l}\text { Long-term stay in municipal } \\
\text { institution }\end{array}$ & $\begin{array}{l}\text { Standard cost estimates } \\
2011 \text { (Kapiainen } \text { et } \\
\text { al.,2014) }\end{array}$ & $202.8 € /$ day \\
\hline $\begin{array}{l}\text { Outpatient visits of hospital including } \\
\text { day surgery }\end{array}$ & $\begin{array}{l}\text { Based on cost function } \\
\text { estimates using individual } \\
\text { level cost data from } \\
\text { Helsinki university hospital }\end{array}$ & $349.2 € /$ visit \\
\hline $\begin{array}{l}\text { Visits to a specialist. In Helsinki visits } \\
\text { to a private specialist }\end{array}$ & $\begin{array}{l}\text { Standard cost estimates } \\
2011 \text { (Kapiainen } \text { et } \\
\text { al.,2014) }\end{array}$ & $286.6 € /$ visit \\
\hline $\begin{array}{l}\text { Visit to a doctor primary care } \\
\text { including home visits. In Helsinki area } \\
\text { visits to health centre doctor and } \\
\text { private non- specialist doctor }\end{array}$ & $\begin{array}{l}\text { Standard cost estimates } \\
2011 \text { (Kapiainen } \text { et } \\
\text { al.,2014) }\end{array}$ & $116.8 € /$ visit \\
\hline $\begin{array}{l}\text { Home care. In Norway assumed } 2 \text { visit } \\
\text { per hour }\end{array}$ & $\begin{array}{l}\text { Standard cost estimates } \\
2011 \text { (Kapiainen } \text { et } \\
\text { al.,2014) }\end{array}$ & $52.0 € /$ visit \\
\hline
\end{tabular}




\section{Appendix Table 2: $\quad$ Descriptive statistics}

\begin{tabular}{|c|c|c|c|}
\hline & & $\begin{array}{l}\text { Helsinki } \\
(\mathrm{n}=3001)\end{array}$ & $\begin{array}{l}\text { Oslo } \\
(\mathrm{n}=3417)\end{array}$ \\
\hline & & mean & mean \\
\hline \multicolumn{4}{|l|}{ Matching and risk adjustment variables } \\
\hline \multirow[t]{9}{*}{ AGE* } & age $50-54$ & $2.1 \%$ & $1.9 \%$ \\
\hline & age $55-59 £ \#$ & $3.8 \%$ & $3.1 \%$ \\
\hline & age $60-64 £ \#$ & $5.7 \%$ & $4.8 \%$ \\
\hline & age $65-69 £ \#$ & $8.4 \%$ & $7.5 \%$ \\
\hline & age $70-74 £ \#$ & $8.7 \%$ & $7.8 \%$ \\
\hline & age $75-79 £ \#$ & $13.3 \%$ & $11.9 \%$ \\
\hline & age $80-84 £ \#$ & $20.1 \%$ & $18.5 \%$ \\
\hline & age $85-89 £ \#$ & $21.2 \%$ & $24.1 \%$ \\
\hline & age over $89 £ \#$ & $16.8 \%$ & $20.3 \%$ \\
\hline Gender* & male£\# & $30.0 \%$ & $29.3 \%$ \\
\hline \multirow[t]{3}{*}{ Type of fracture* } & S72.0 & $60.1 \%$ & $60.1 \%$ \\
\hline & S72.1£\# & $35.2 \%$ & $34.6 \%$ \\
\hline & $\mathrm{S} 72.2 £ \#$ & $4.6 \%$ & $5.4 \%$ \\
\hline \multirow[t]{6}{*}{ Cohort year* } & 2009 & $16.5 \%$ & $18.9 \%$ \\
\hline & 2010£\# & $16.8 \%$ & $17.4 \%$ \\
\hline & $2011 £ \#$ & $17.6 \%$ & $15.8 \%$ \\
\hline & 2012\# & $17.5 \%$ & $17.3 \%$ \\
\hline & 2013\# & $16.9 \%$ & $16.2 \%$ \\
\hline & 2014\# & $14.9 \%$ & $14.5 \%$ \\
\hline \multirow{4}{*}{$\begin{array}{l}\text { Number of days in different care arrangements } \\
\text { within } 90 \text { days before index admission* }\end{array}$} & Hospital day\# & 0.7 & 0.5 \\
\hline & Long-term days\$\# & 6.2 & 4.5 \\
\hline & $\begin{array}{l}\text { Days at home with } \\
\text { home help\$ \# }\end{array}$ & 15.2 & 27.7 \\
\hline & $\begin{array}{l}\text { Days at home without } \\
\text { home help }\end{array}$ & 67.9 & 57.3 \\
\hline Annual gross income* & & 22541 & 28443 \\
\hline \multirow[t]{3}{*}{ Education* } & Basic & $52.6 \%$ & $33.6 \%$ \\
\hline & Secondary\# & $20.8 \%$ & $45.9 \%$ \\
\hline & Upper\# & $26.5 \%$ & $20.5 \%$ \\
\hline
\end{tabular}




\section{Appendix Table 2: $\quad$ Descriptive statistics (continued)}

\section{Performance variables}

\begin{tabular}{|c|c|c|}
\hline \multicolumn{3}{|l|}{ Length of stay } \\
\hline $\begin{array}{l}\text { Length of first acute } \\
\text { hospital admission** }\end{array}$ & 8.8 & 11.1 \\
\hline $\begin{array}{l}\text { Length of first } \\
\text { institutional episode } * * \\
\text { Service use }\end{array}$ & 39.2 & 39.1 \\
\hline $\begin{array}{l}\text { Number of inpatient } \\
\text { days, one year*** }\end{array}$ & 93.7 & 93.6 \\
\hline $\begin{array}{l}\text { Number of GP visits, } \\
\text { one year*** }\end{array}$ & 2.0 & 4.1 \\
\hline $\begin{array}{l}\text { Number of other health } \\
\text { care visits, one year } \$ \\
* * *\end{array}$ & 5.9 & 1.0 \\
\hline $\begin{array}{l}\text { Number of home care } \\
\text { visits one year*** } \\
\text { Emplacement }\end{array}$ & 91.8 & 127.6 \\
\hline $\begin{array}{l}\text { Share of patients } \\
\text { discharged home (total } \\
\text { ) within } 90 \text { days**** }\end{array}$ & $67.0 \%$ & $65.7 \%$ \\
\hline $\begin{array}{l}\text { Share of patients } \\
\text { discharged home } \\
\text { (without help) within } \\
90 \text { days } * * * *\end{array}$ & $42.3 \%$ & $38.2 \%$ \\
\hline $\begin{array}{l}\text { Share of patients } \\
\text { institutionalised ( } 90 \\
\text { days) })^{* *}\end{array}$ & $17.3 \%$ & $18.0 \%$ \\
\hline $\begin{array}{l}\text { Share of patients } \\
\text { institutionalised (one } \\
\text { year)*** } \\
\text { Cost }\end{array}$ & $7.7 \%$ & $9.2 \%$ \\
\hline $\begin{array}{l}\text { Cost of first hospital } \\
\text { episode } * *\end{array}$ & 16684 & 17170 \\
\hline One year cost $* * *$ & 38073 & 38157 \\
\hline \multicolumn{3}{|l|}{ Mortality } \\
\hline 30-day mortality* & $6.7 \%$ & $5.3 \%$ \\
\hline 90-day mortality** & $11.8 \%$ & $11.4 \%$ \\
\hline One-year mortality $* * *$ & $20.8 \%$ & $21.3 \%$ \\
\hline
\end{tabular}

$£$ Used as control variables in risk adjusted figures and difference-in-difference analysis (except year indicators which are coded based on timing and place of the intervention). Model M1

\# Used as control variables in risk adjusted figures and difference-in-difference analysis (except year indicators which are coded based on timing and place of the intervention). Model M2

* Excluded patients with index day in December 2014 (n Helsinki=3001; n Oslo=3417)

**Excluded patients with index day after the first of October in 2014 (n Helsinki=2908; n Oslo=3330)

$* * *$ Excluded patients with index day in 2014 (n Helsinki=2555; n Oslo=2923)

$* * * *$ Excluded patients with index day after mid-September in 2014 (n Helsinki=2888; n Oslo=3271)

$\$$ Visits to specialist, emergency and outpatient departments of hospitals 